\title{
La configuración de nuevos racismos: relatos y discursos de una comunidad universitaria
}

\author{
Natalia Ayala Lenis \\ Laura Barona Lame \\ (nathaliaayalal@gmail.com) \\ (lauraba_1994@hotmail.com) \\ Angélica María Contreras \\ Diana Paola Salazar Arana \\ (angelicacontrerasm@hotmail.com) \\ (dianasalazar.1996@gmail.com)
}

Artículo corto de investigación recibido el 06/12/2015 y aprobado el 19/05/2016.

Cómo citar este artículo:

AYALA LENIS, Natalia; BARONA LAME, Laura;CONTRERAS, Angélica María ; y SALAZAR ARANA, Diana Paola (2016). "La configuración de nuevos racismos: relatos y discursos de una comunidad universitaria". En: Trans-pasando Fronteras, Núm. 10, pp. 67-75. Cali, Colombia: Centro de Estudios Interdisciplinarios, Jurídicos, Sociales y Humanistas (CIES), Facultad de Derecho y Ciencias Sociales, Universidad Icesi.

\section{Resumen}

Este artículo parte de un análisis de entrevistas realizadas en un recinto universitario, de donde se puede observar una reconfiguración del racismo en las prácticas y discurso que se han hido naturalizando a través del lenguaje y comportamientos que dejan en evidencia una clara racionalización de la existencia de la noción de "raza" como esencia de dominación y segregación de diversos grupos sociales, aún al interior de una comunidad universitaria.

\section{Palabras claves:}

Nuevos racismos, comunidad universitaria, relatos, discursos. 


\section{Introducción}

La evidencia cotidiana que presenta este ensayo se basó en la realización de entrevistas a cinco personas que hacen parte de una comunidad universitaria. ${ }^{1}$ En tres de ellas se entrevistaron a una conserje con veinte años de servicio a la universidad; una joven colaboradora de servicios de aseo; y una ayudante de cocina de uno de las cafeterías de la Universidad, todas ellas, mujeres que se reconocían afrodescendientes. Las otras dos entrevistas se realizaron a un estudiante de cuarto semestre de pregrado en Medicina y a un profesor del programa de Química. ${ }^{2}$

Según Fredrickson (2002), los racismos se configuran a partir de las modificaciones históricas, adquiriendo la capacidad de adaptarse a los cambios de discursos para mantener vigentes las clasificaciones que generan un orden social. En su texto "Racism: a short history", el autor menciona que la nueva configuración del racismo se da precisamente bajo una ilusión de neo-racismo, como es el claro ejemplo de la sociedad occidental. Es así como en nuestro hemisferio coexisten la discriminación y la desigualdad, bajo un paradigma de sociedad que declara públicamente la libertad y la igualdad humana. ${ }^{3}$ A partir de los relatos recogidos dentro del recinto universitario, se puede observar cómo desde diferentes lugares, el racismo se está reconfigurando dentro del campus a través de expresiones del lenguaje y del comportamiento que han sido naturalizados, pero con una clara racionalización que da cuenta de la existencia de la noción de "raza" en la Universidad.

La palabra "raza", ha tenido históricamente una importancia significativa en las teorías científicas, las cuales a través de sus discursos, establecen diferencias biológicas acorde a las características físicas de las personas como diferencias sociales entre grupos humanos como referente para la formación de jerarquías, identidades y roles sociales (Hering, 2007; Mosquera Becerra, 2015: 113). Asimismo bajo ese patrón de dominación, se fomenta todo tipo de prácticas exclusorias que terminan acentuando las brechas de bienestar social entre

1 Se omiten nombres y detalles que pueden permitir identificar a los entrevistados por ausencia de un permiso por escrito para ello; no obstante, sí existió consentimientos verbales para el registro de las entrevistas.

2 Ver el estudio de Vanessa Ortiz Piedrahíta (2013), quien también a apartir de entrevistas, indaga sobre las diferencias raciales que percibe un grupo de mujeres universitarias afrodescendiente sobre su cuerpo y apariencia, en relación con el ideal de belleza hegemónico contemporáneo.

3 Principios que generan un escenario que permite que sean las razones culturales e individuales las que explique la desigualdad racial (Mullings, 2013). 
las etnias. Es por lo anterior que las prácticas racistas dotan a la idea de "raza" de una flexibilidad para ser un concepto dinámico, polisémico, adaptable y a su vez cambiante con el tiempo (Cadena, 2007). A pesar de esto, sigue permaneciendo la esencia de dominación y segregación de diversos grupos sociales.

En la actualidad es comprobable que para los científicos de la genética y de las ciencias sociales, la pigmentación de la piel no determina funciones y comportamientos diferentes del ser humano y que todos formamos parte de la humanidad sin que exista algún grupo superior a otro. Por el contrario, existen estudios que han mostrado la poca fiabilidad de explicar variaciones genéticas a partir de un concepto tan ambiguo como el de raza, por ejemplo, el Doctor en Ciencias Biológicas de la Universidad de La Habana, Antonio Martínez, y la Especialista de II Grado en Medicina General Integral, Invonne Fernández, reconocen un nuevo marco para estudiar las variaciones genéticas a partir de factores históricos, ambientales y sociales, como lo hacen al proponer:

La utilidad, precisión y beneficio de analizar las variaciones entre los grupos humanos en términos de variaciones en la frecuencias de sus genes y en su relación con los factores histórico-sociales y culturales, más que a partir del impreciso y obsoleto concepto biológico de raza, el cual interfiere con el estudio objetivo de ciertas enfermedades y no funciona como una herramienta eficiente en la investigación biomédica. El organismo humano está inmerso en un ambiente social cuyas características pueden favorecerlo o limitarlo. Así, un ambiente adverso, caracterizado por situaciones carenciales en la nutrición, la atención médica, la salubridad, etc., unidas a un estado de estrés social, se refleja en el mal estado físico-biológico y de salud de los integrantes de la sociedad (Martínez y Fernández, 2006: 6)

A pesar de estos avances en la forma de analizar e interpretar las diferencias biológicas y genéticas entre los seres humanos, en el gremio de las ciencias de la salud se mantiene la tendencia a hablar de "razas" y no de etnias o culturas, aunque la raza sea un constructo ideológico repleto de inconsistencias y arbitrariedades. En este caso de estudio, se advierten planteamientos en las Facultad de Ciencias Naturales y de Medicina, que reafirman la racionalización de los planteamientos con determinismo biológico. Este es el caso de un profesor vinculado a la Facultad de Ciencias Naturales, quien afirma que: 
"desde el punto de vista genético, existen diferentes linajes genéticos, fundamentados en los genomas de cada individuo, que dependen del proceso selectivo de la evolución".

Sin embargo, aunque él aclara que su definición de "raza" no tiene nada que ver con la definición sociológica, sino que se relaciona con un fundamento biológico, desde nuestro punto de vista, retoma la construcción científica de la existencia de "razas" inferiores estableciendo a su vez, jerarquías raciales. Un ejemplo de lo anterior se encuentra en la idea que sostiene el profesor cuando dice que la genética determina las enfermedades a las que una persona está más propenso a adquirir, o que la pigmentación de la piel ayuda a desarrollar cierto tipo de resistencia al sol, pero que "estas son solamente leves diferencias en nuestro linaje genético, las cuales no tienen que ver con la configuración de la sociedad". Según el profesor, eso ya depende de nuestros propios prejuicios. Estas afirmaciones no son exclusivas del profesor, en la entrevista con un estudiante de medicina de cuarto semestre, se corrobora la existencia de estos discursos en la facultad cuando afirma que:

"En lo concierne a profesores y estudiantes de medicina, sí distinguimos que hay diferentes razas y que cada uno tiene un componente genético, y por consiguiente fisiológico, distintos y que debido a eso tienen cierta prevalencia de enfermedades".

Entre las enfermedades que mencionan, se encuentran la hipertensión, los lunares en los ojos y la tendencia a tener la esclera amarilla. De esta manera es que, en un contexto pos-racial, se legitiman prácticas racistas no intencionales con argumentos que históricamente han justificado la superioridad de las "razas".

A pesar de que no existe una intencionalidad de los entrevistados de generar efectos en la vida social a partir de sus argumentos científicos, la literatura sobre el tema nos dice que no existe racismo sin teorías, las cuales incluyen argumentos que están "racionalizados" por los intelectuales. De forma que, "las teorías del racismo oculto simulan el discurso científico basándose en 'evidencias' visibles (de ahí la importancia 
fundamental de los estigmas de la raza y, especialmente, de los estigmas corporales)" (Balibar \& Wallerstein, 1991: 34). En este sentido, los argumentos científicos en los que se basan los médicos para señalar factores biológicos como criterio de diferenciación racial, ${ }^{4}$ señalan un aspecto del nuevo racismo en nuestra Universidad, en la que se retorna a la cuestión biológica, donde se elaboran nuevas variantes o se retoman antiguas del "mito" biológico dentro del marco de un racismo cultural (Balibar \& Wallerstein, 1991), lo que conlleva a que se acentúen las diferencias entre comunidades.

Ahora bien, la idea de "raza" perdura en la sociedad no sólo por causa de los argumentos científicos, sino también debido a los sistemas racializados que a su vez son reforzados por la gramática racial (estereotipos y prejuicios basados en el ideal de la blancura) existente en las estructuras sociales. Esta racialización del cuerpo, que incluye elementos psicológicos, es según Fanon una “epidermización de la raza”, lo cual representa un proceso más profundo y violentamente dañino que el proceso relacionado con los discursos de la diferencia cultural (Barot \& Bird, 2001). La racialización permite entender mejor la discriminación racial, creando estados psicológicos y puntos de vista del cuerpo, donde se toman características que son atribuidas a grupos socialmente racializados, destacando aspectos biológicos que distinguen a unos cuerpos de otros por sus rasgos físicos, genéticos, fisiológicos y epidemiológicos -como lo afirmó un estudiante de cuarto semestre de medicina-, que intentan explicar la propensión de ciertas "razas" hacia determinadas enfermedades. Este fenómeno de racialización también se encontró en los discursos recolectados en la Universidad, aunque la mayoría de ellos se enunciaron bajo una negación de la existencia de racismos.

En este punto del análisis, es pertinente acudir al concepto de gramática racial y de naturalización del comportamiento racista, como ese aspecto de la dominación que ayuda a normalizar los estándares y discursos de supremacía blanca en la sociedad, ayudando a reproducir el orden racial (Bonilla-Silva, 2012). La especificidad de la gramática racial, es que logra insertarse en el lenguaje de una manera cotidiana, generando lo que Bonilla-Silva (2012) denomina The Invisible Weight of Whiteness. La explicación de la gramática racial

4 En los relatos recogidos, se afirma la proclividad de ciertos grupos de la población -afros en este caso- a padecer de enfermedades específicas, como la hipertensión y la anemia, más que los blancos, como se ve en algunas entrevistas realizadas (a estudiantes de medicina y un profesor), 
y sus formas de operar, ayudan a dar sentido a las expresiones de Doña C. -trabajadora de una de las cafeterías- quien afirma no tener ningún problema con el apodo que tiene en el trabajo "si me dicen negra pues soy negra, si me dicen bonita pues soy bonita, cuál es el problema”. Contrario a sus afirmaciones, el peso invisible de la blancura sí está reflejado en la vida cotidiana de esta mujer, quien a pesar de la personalidad despreocupada y arrolladora que refleja tener, reconoce que lo único que le molesta de su cuerpo es su "cabello de negra", el cual debe alizar para "poder que no se le partan las peinetas".

El peso invisible de la blancura también se registra en el relato del estudiante J., quien haciendo un recuento de sus experiencias en la Universidad (durante 5 años), cuenta cómo él y otro estudiante afro fueron víctimas de las acusaciones del personal de mantenimiento de la Universidad. En palabras del estudiante, se afirma que una señora del aseo nos trató mal a mí y a otro compañero que era más oscuro, porque estábamos tomando agua de uno de los carritos y dijo - ¡Ahhh váyanse de aquí, por qué se metieron a robar!-y nosotros quedamos perplejos y respondimos -somos estudiantes-. En otro relato, un estudiante recuerda cómo un profesor en clase señaló la presencia de "un negro" (él) como ejemplo de los esfuerzos de inclusión que estaba haciendo la Universidad.

Esta tendencia a ver la presencia de personas afrocolombianas como "inclusión" en la Universidad, no sólo genera un peso invisible de la blancura en los estudiantes afro, sino que también muestra la existencia de imaginarios racializados del lugar que ocupan los afrocolombianos en nuestra sociedad. Por esto, según el discurso de otra estudiante, el aumento de presencia de estudiantes afros en la Universidad responde al aumento de las becas, y a la creación del programa ser pilo paga. La aparente "correlación" entre ser afro y provenir de un estrato socioeconómico específico (establecida por esta estudiante), da cuenta de la existencia de unas geografías racializadas y también de una posible jerarquización en las ocupaciones.

Este imaginario de jerarquización del trabajo y de diferenciación socioeconómica a partir de patrones "raciales", encuentra una explicación en la literatura. Por ejemplo, para Quijano (2010) la "raza" es el resultado de la dominación colonial de los europeos y los nativos americanos, estableciendo así relaciones de superioridad a través de las diferencias fenotípicas como el color de la piel. Es así como la pigmentación de la piel toma un rol importante ante la necesidad de diferenciar el "Yo" del "Otro" para el beneficio del 
naciente sistema mundo capitalista, el cual favorecería la mercantilización y explotación de la fuerza de trabajo a través del supuesto que el color estaría anclado a una ocupación determinada. Por lo tanto, para él la raza "es el más eficaz instrumento de dominación social inventado en los últimos 500 años" (Quijano, 2010: 183).

En los relatos recogidos dentro de la Universidad, la conserje F.(quien ha trabajado durante 20 años en la Universidad), hace algunas distinciones de la composición étnica de las diferentes profesiones que ha visto en la Universidad. Como primer elemento, menciona que es común ver población afrodescendiente laborando en oficios varios, consejería, seguridad y cafeterías, mientras que en las facultades son pocos los profesores afros que ve; al respecto reconoce: "allá por idiomas, en el segundo piso del A, al fondo". También dice que "en educación continua estuve atendiendo unos profesores que venían con trajes típicos y de afrocolombianidad, pero en el resto de facultades que yo haya visto, no". Además de la jerarquización de las profesiones con un patrón racial, el concepto de racialización destacado por Barot y Bird (2001), "consiste en formas de relación de poder/conocimiento que se centran en el cuerpo y los procesos de sujeción. Las jerarquías se establecen con referencia a las jerarquías biológicas, higiénicas, culturales y ambientales" (Goldberg en Barot \& Bird, 2001: 608-609). En las experiencias de vida de F., el peso de 20 años de profesión han dejado marcas en su salud, generándole tres cirugías reconocidas bajo la ARL, y un evidente agotamiento por el esfuerzo físico y la poca remuneración.

La construcción de los cuerpos y las mentes, también aparece en los relatos recogidos en la Universidad bajo la promulgación de una diferenciación a partir de la cultura, las costumbres y las formas de vida. Dentro de esta diferenciación, se registran argumentos en la Universidad con una tendencia a folclorizar el lugar de las comunidades afrocolombianas en nuestra sociedad. Por ejemplo, parte del personal administrativo de la Facultad de Ciencias Naturales, reconoció rápidamente en la entrevista que las comunidades afros se destacan en actividades corporales como la Danza, por una predisposición "natural".

En la cotidianidad de las dinámicas universitarias, las configuraciones del lenguaje que apelan a una imagen estereotipada del lugar de la afrocolombianidad en el país, se ven reflejadas en los espacios de cuenteros semanales dentro del campus. Al respecto, uno 
de los estudiantes entrevistados, quien se auto-reconoce como afrocolombiano y quien además hace parte del espacio de cuenteros, reconoció que usa constantemente chistes con referencia a los afros como "en esta Universidad no pueden haber más de tres negros en un salón porque se activa la alarma". Al respecto, afirmó que lo hace no sólo para generar risa, sino porque "en parte es una forma de hacer un llamado de atención sobre la falta de inclusión". Sobre este mismo tema, otra estudiante afirmó que siempre que va a los espacios de cuentería hay un chiste racista, machista, homofóbico, que genera risa en la gente y que no sabe "hasta qué punto la universidad debe permitirlo".

De acuerdo con la creciente preocupación por la cuestión racial, se han atravesado por cambios importantes a nivel institucional. En este sentido, las dinámicas de la Universidad 15 años atrás, no son las mismas de hoy. La Universidad se ha transformado y las interacciones están cambiando gracias a la sencibilización que han generado los centros de estudio y pensamiento en temas afrodispóricos en la comunidad universitaria. ${ }^{5} \mathrm{Sin}$ embargo, parece que este es un rasgo particular de los centros de estudios de algunas Facultades, pues en otras, principalmente aquellas que se relacionan con las ciencias de la salud, los relatos recogidos para este trabajo registran la continuación de un discurso racista, basado en argumentos biológicos para legitimar la existencia de razas y la tendencia de algunas de ellas hacia enfermedades específicas. Estas justificaciones biológicas, que en palabras de quienes las enuncian no tienen impacto en la vida social, sí coexisten con la racialización de los cuerpos y de las profesiones dentro de la Universidad, generando una consolidación de fenómenos como el neo-racismo, el cual se oculta bajo prácticas y discursos naturalizados, pero con efectos reales en la vida cotidiana de quienes sufren este tipo de discriminación al interior de la Universidad.

\section{Referencias}

Barot, R. \& Bird, J. (2001). Racialization: the genealogy and critique of a concept. Ethnic and racial Studies. 24(4), pp.601-618

5 En la entrevista con la señora F., quien cuenta con más de 20 años de experiencia trabajando en la universidad, se enuncia que se advierte este cambio de sencilbilización frente a esto temas a raíz de la existencia de centros que estudien esos temas. 
Balibar, E. \& Wallerstein, I. (1991). Chapter 4. Race, Nation and Class. Ambiguous Identities. London: Verso.

Bonilla-Silva, E. (2012) The invisible weight of whiteness: the racial grammar of everyday life in contemporary America. Ethnic and Racial Studies, 35(2): 173-194

Cadena, Marisol de la. (2007). Formaciones de indianidad: Articulaciones raciales, mestizaje y nación en América Latina. Colombia: Envión.

Fernández \& Martínez (2006) ¿Es la raza un criterio útil en la práctica médica? Revista Cubana de Medicina General Integral, 22(1)

Frederickson, George M. (2002). Appendix. Racism: A Short History. Princeton: Princeton University Press.

Hering Torres, M. S. (2007). "Raza": Variables Históricas. Revista de Estudios Sociales, (26), 16-27.

Leal, C., \& Arias, J. (2007). Aproximaciones a los estudios de raza y racismo de Colombia. Revista de Estudios Sociales, (27), 184-193.

Mosquera Becerra, J. (2015). Develando lo que dicen sobre raza y etnia las revistas de salud pública de Colombia. Revista CS, (16), pp. 109-129. DOI: http://dx.doi. org/10.18046/recs.i16.1939

Mullings, L. (2013). Interrogando el racismo. Hacia una Antropología antirracista. Revista CS, (12), pp. 325-375. DOI: http://dx.doi.org/10.18046/recs.i12.1683

Ortíz Piedrahita, V. (2013). Percepciones y prácticas corporales estéticas de un grupo de jóvenes universitarias Afrodescendientes de Cali. Revista CS, (12), pp. 85-125. DOI: http://dx.doi.org/10.18046/recs.i12.1678

Quijano, A. (2010). ¡Qué tal raza! En: Mosquera Rosero, Claudia, Agustín Laó-Montes y César Rodríguez Garavito (eds.). Debates sobre ciudadanía y políticas raciales en las Américas Negras. Bogotá, D.C, Colombia: Universidad Nacional de Colombia. Universidad del Valle. 